\title{
The features of acute lymphocytic leukemia with intracranial germinoma in a patient with Li-Fraumeni syndrome: a case description
}

\author{
Yiwen Liang ${ }^{1}, \mathrm{Ke} \mathrm{Wei}^{1,2}$, Weiguo Cao ${ }^{1}$ \\ ${ }^{1}$ Department of Radiology, Shenzhen Children's Hospital, Shenzhen, China; ${ }^{2}$ China Medical University, Shenyang, China \\ Correspondence to: Weiguo Cao. Department of Radiology, Shenzhen Children's Hospital, 7019, Yitian Road, Futian District, Shenzhen, 518038, \\ China. Email: weiguo.cao@126.com.
}

Submitted Jun 11, 2021. Accepted for publication Nov 05, 2021.

doi: 10.21037/qims-21-614

View this article at: https://dx.doi.org/10.21037/qims-21-614

\section{Introduction}

Germline pathogenic mutations in the Protein p53 (TP53) gene can be detected in $70-80 \%$ of Li-Fraumeni syndrome (LFS) patients. Common tumors in LFS patients include premenopausal breast cancer, bone and soft tissue sarcomas, central nervous system (CNS) tumors, leukemia, and adrenocortical carcinomas $(1,2)$. In LFS patients, the risk of developing a second tumor is $57 \%$, and the risk of developing a third tumor is $38 \%$ (3). In children with LFS, the incidence of CNS tumors, including glioblastomas and other gliomas, choroid plexus papillomas, medulloblastomas, and ependymomas, is approximately $81 \%$, while the incidence of hematological tumors, such as diploid acute lymphoblastic leukemia (ALL), acute myelocytic leukemia, and myelodysplastic syndrome, is only about $4 \%(3,4)$. In a study involving 3,801 children with ALL, LFS-ALL accounted for $<1 \%$ of the ALL cases (5). To date, intracranial germinoma in LFS has rarely been reported.

\section{Case presentation}

An 8-year-old boy was admitted to our hospital complaining of intermittent muscle pain for 1 month and bleeding from his left ear for 3 days. Magnetic resonance imaging (MRI) of the left shoulder showed abnormal bone signals in the diaphysis and metaphysis of the left humerus, suggesting a diagnosis of a hematologic disease. B-cell ALL was identified following a bone marrow biopsy. Brain MRI showed a pineal lesion (see Figure 1). The tumor markers displayed no abnormalities. The pineal lesion cause was thought to be leukemia infiltration. Afterwards, the patient received chemotherapy [according to the China Children Oncology Group (CCCG)-ALL-2015, 2019 version], and successfully entered the maintenance phase.

Some 2 years later, the patient developed headache and vomiting. MRI showed an enlarged pineal lesion and a mass in the sellar area and spinal cord (see Figure 2). Cerebrospinal fluid showed Alpha-fetoprotein (AFP) $=0.48 \mathrm{ng} / \mathrm{mL}$, and $\beta$-Hepatocellular $(\beta-\mathrm{HCG})=150.16 \mathrm{mIU} / \mathrm{mL}$. A pineal lesion biopsy confirmed grade IV germinoma as per the World Health Organization's guidelines. Due to limitations of the pathological examination results of the biopsy, the patient was diagnosed with pineal non-germinomatous germ cell tumor (GCT) with sellar area and spinal cord metastasis.

Following detailed questioning to obtain the patient's family history, we learned that the patient's family had a history of cancer. Specifically, the patient's aunt died of colon cancer at the age of 24 years, the patient's father died of lymphoma, liver cancer, and cholangiocarcinoma at the age of 39 years, and the patient's grandfather died of lung cancer at the age of 48 years. Bone marrow aspirate samples from the patient were taken for TP53 mutation detection, and the results showed that there was a c. $524 \mathrm{G}$ $>\mathrm{A}(\mathrm{p} \cdot \mathrm{R} 175 \mathrm{H})$ pathogenic mutation, which is a missense mutation (with a mutation frequency of $51.2 \%$ ). A karyotype analysis of the bone marrow cells showed a karyotype of 46, XY. Through further consultation with a geneticist, it 
was determined that the patient met the Chompret criteria for LFS.

As the patient had been diagnosed with germinoma, he had been receiving etoposide and cisplatin chemotherapy. A 4-month follow-up examination revealed that the sellar area and spinal cord masses had disappeared, but the pineal tumor had only reduced from 2.5 to $2.0 \mathrm{~cm}$ (at its maximum diameter), thus its removal was recommended.

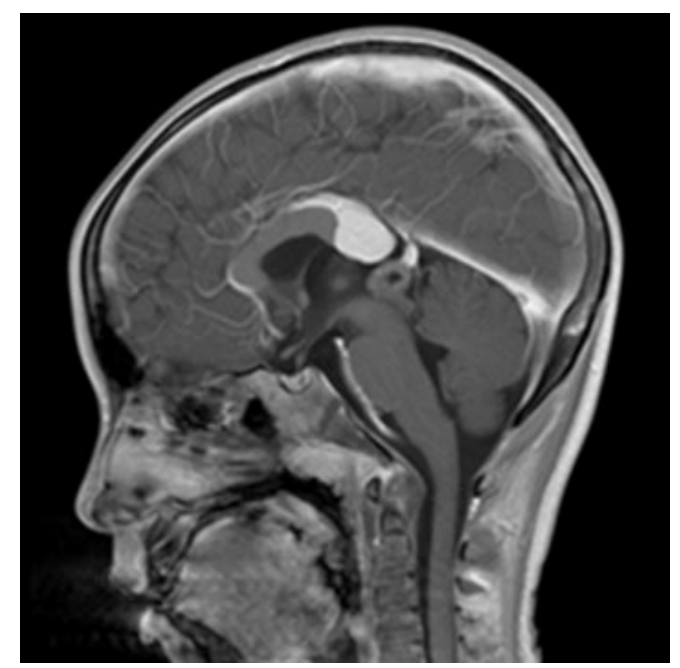

Figure 1 Contrast-enhanced brain MRI showed a mixed signal mass in the pineal gland with mild enhancement. Lipoma in the midline region and dysplasia of the corpus callosum were also observed.
All of the procedures performed in this study involving the patient were conducted in accordance with the ethical standards of the institutional and/or national research committee(s) and the Helsinki Declaration (as revised in 2013). Written informed consent was obtained from one of the patient's parents for the publication of this article and the accompanying images. A copy of the written consent form is available for review by the editorial office of this journal.

\section{Discussion}

Intracranial GCT and ALL are highly sensitive to radiotherapy and chemotherapy. Chemotherapy induces apoptosis through DNA damage caused by TP53, thus triggering an anti-tumor response (6). However, TP53 mutations prevent cell-cycle arrest and DNA repair, leaving tumor cells unable to produce an apoptotic response after exposure (7). Thus, TP53 mutation may have been the cause of the multiple primary tumors and cisplatin insensitivity in this patient. Studies have shown that chemotherapy can increase the risk of secondary tumors (7). Treating patients with multiple tumors can be very challenging. In this case, the treatment choice of the patient was at the discretion of the physician, and was monitored based on the patient's condition. According to the United Kingdom Cancer Genetics Group (UKCGG), monitoring the presence of TP53 pathogenic variants requires additional follow-up examinations with patients to ensure the detection and
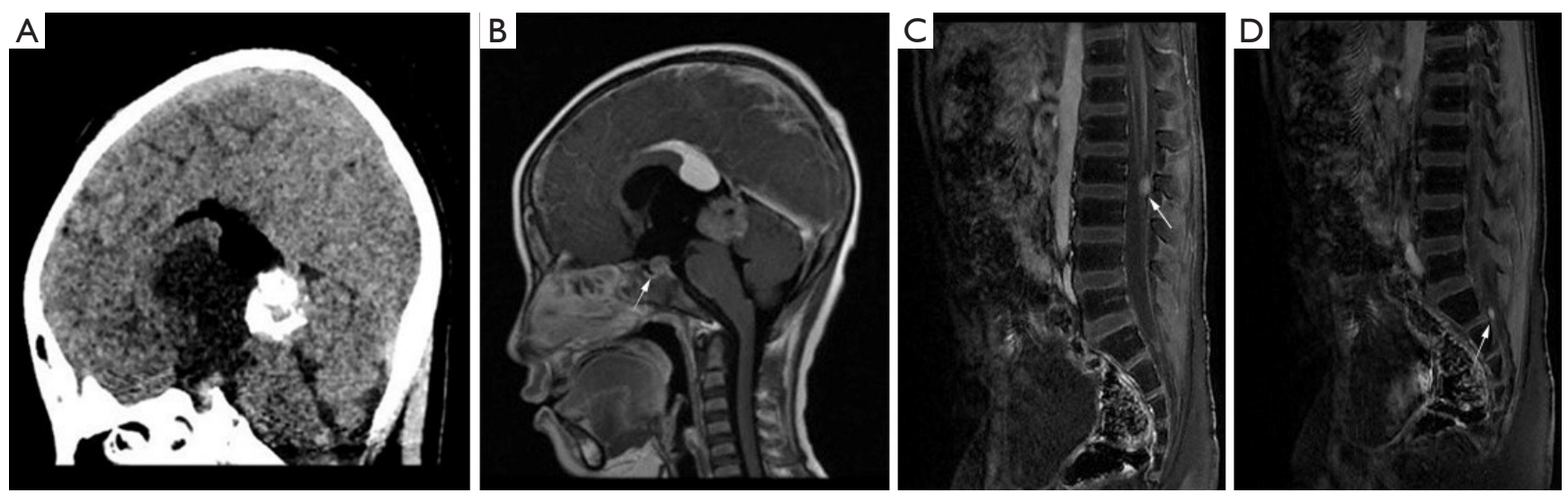

Figure 2 A sagittal brain scan (A) showed a mass in the pineal with numerous calcifications and supratentorial hydrocephalus. MRI of the brain (B), lumbar spine (C), and sacrum and coccyx (D) showed that the pineal mass was significantly more enlarged than it had been previously on T1 weighted image (T1WI), and mild heterogeneous enhancement and the compression of adjacent tissues were also observed, the small nodular (arrows) in the sellar area and L2-3 and S1 vertebral level intraspinal were slightly enhanced. 
prevention of lesions (8).

In this case, we thought pineal lesion was the result of ALL infiltration and prioritized the treatment of the leukemia upon discovering the pineal mass. Unfortunately, we failed to recheck the brain MRI during the leukemia treatment. Indeed, the patient was not re-examined until he presented with the symptoms of headache and vomiting. Thus, this case study provides an important lesson from which we should all learn. Specifically, this case study highlights the importance of differentiating ALL infiltration from germinoma, as they require different therapies. About 3-8\% of ALL patients have CNS infiltration (9). CNS infiltration is common in the remission stage and is often characterized by diffuse leptomeningeal infiltration; however, intracranial space occupying lesions and spinal cord involvement are rare (10). When we found a mass on the saddle and pineal gland at the same time, the diagnose was able to be confirmed without a biopsy. A double lesion may also be caused by the metastatic spread of the sellar area or pineal gland lesion rather than synchronous occurrence (11). Thus, when an intracranial mass is found in ALL children, a comprehensive diagnosis should be made according to the imaging and clinical manifestations.

ALL mostly occurs in children aged 2-5 years (12). However, ALL patients with TP53 gene mutations are significantly older at the time of onset and often have a low diploid karyotype (3). A good treatment response can be achieved during the initial stages of treatment, but the treatment results are extremely poor and patients with TP53 mutations are more prone to relapse than patients with ALL alone (13). In this case, the patient achieved a good therapeutic effect and successfully reached the maintenance treatment period. Thus, the issue of whether the therapeutic effect in this child was related to the selection of treatment options or karyotype chromosome differences requires further study.

In conclusion, ALL complicated with intracranial GCT is rare, but a detailed family history and relevant clinical history should be obtained to ensure early diagnosis and prevention to improve the survival rate of patients.

\section{Acknowledgments}

Funding: This work was supported by the Sanming Project of Medicine in Shenzhen (SZSM202011005).

\section{Footnote}

Conflicts of Interest: All authors have completed the ICMJE uniform disclosure form (available at https://dx.doi. org/10.21037/qims-21-614). The authors have no conflicts of interest to declare.

Ethical Statement: The authors are accountable for all aspects of the work, ensuring that any questions related to the accuracy or integrity of any part of the work are appropriately investigated and resolved. All procedures performed in this study involving human participants were conducted in accordance with the ethical standards of the institutional and/or national research committee(s) and the Helsinki Declaration (as revised in 2013). Written informed consent was obtained from the patient's parent for the publication of this article and the accompanying images. A copy of the written consent form is available for review by the editorial office of this journal.

Open Access Statement: This is an Open Access article distributed in accordance with the Creative Commons Attribution-NonCommercial-NoDerivs 4.0 International License (CC BY-NC-ND 4.0), which permits the noncommercial replication and distribution of the article with the strict proviso that no changes or edits are made and the original work is properly cited (including links to both the formal publication through the relevant DOI and the license). See: https://creativecommons.org/licenses/by-nc-nd/4.0/.

\section{References}

1. Gargallo P, Yáñez Y, Segura V, et al. Li-Fraumeni syndrome heterogeneity. Clin Transl Oncol 2020;22:978-88.

2. Orr BA, Clay MR, Pinto EM, et al. An update on the central nervous system manifestations of Li-Fraumeni syndrome. Acta Neuropathol 2020;139:669-87.

3. Dutzmann CM, Vogel J, Kratz CP, et al. Update on LiFraumeni syndrome. Pathologe 2019;40:592-9.

4. Bougeard G, Renaux-Petel M, Flaman JM, et al. Revisiting Li-Fraumeni Syndrome From TP53 Mutation Carriers. J Clin Oncol 2015;33:2345-52.

5. Winter G, Kirschner-Schwabe R, Groeneveld-Krentz S, et al. Clinical and genetic characteristics of children with acute lymphoblastic leukemia and Li-Fraumeni syndrome. 
Leukemia 2021;35:1475-9.

6. Nishimoto M, Ohara K, Kamamoto D, et al. Tumor immune microenvironment is associated with the growth of intracranial germinomas. J Neurooncol 2020;146:139-46.

7. Ottaviano M, Giunta EF, Rescigno P, et al. The Enigmatic Role of TP53 in Germ Cell Tumours: Are We Missing Something? Int J Mol Sci 2021;22:7160.

8. Hanson H, Brady AF, Crawford G, et al. UKCGG Consensus Group guidelines for the management of patients with constitutional TP53 pathogenic variants. J Med Genet 2020. [Epub ahead of print].

9. Zhou F, Wen Y, Jin R, et al. New attempts for central nervous infiltration of pediatric acute lymphoblastic leukemia. Cancer Metastasis Rev 2019;38:657-71.

10. Kudoh T, Otoi H, Suzuki N, et al. Simultaneous development of a pineal tumor and an intradural spinal

Cite this article as: Liang Y, Wei K, Cao W. The features of acute lymphocytic leukemia with intracranial germinoma in a patient with Li-Fraumeni syndrome: a case description. Quant Imaging Med Surg 2022;12(3):2189-2192. doi: 10.21037/qims-21614 mass during remission of acute lymphocytic leukemia. Jpn J Clin Oncol 2000;30:105-8.

11. Phi JH, Kim SK, Lee J, et al. The enigma of bifocal germ cell tumors in the suprasellar and pineal regions: synchronous lesions or metastasis? J Neurosurg Pediatr 2013;11:107-14.

12. Jacola LM, Krull KR, Pui CH, et al. Longitudinal Assessment of Neurocognitive Outcomes in Survivors of Childhood Acute Lymphoblastic Leukemia Treated on a Contemporary Chemotherapy Protocol. J Clin Oncol 2016;34:1239-47.

13. Hof J, Krentz S, van Schewick C, et al. Mutations and deletions of the TP53 gene predict nonresponse to treatment and poor outcome in first relapse of childhood acute lymphoblastic leukemia. J Clin Oncol 2011;29:3185-93. 